\title{
Quantification of Doxycycline in Raw Material by an Eco-Friendly Method of Infrared Spectroscopy
}

Ana Carolina Kogawa*, Natalia Prudente de Mello and Hérida Regina Nunes Salgado

Department of Pharmaceutics, School of PharmaceuticalSciences of Araraquara, Univ Estadual Paulista - UNESP, Araraquara, São Paulo, Brazil

\begin{abstract}
Doxycycline is a broad spectrum antibiotic used in the treatment of infectious diseases in humans and animals. It is distributed free of charge, by medical prescription, in Brazil through the public health system. Thus, since a considerable number of people have access to this drug, it is of great interest to control its quality. The purpose of the research was the development and validation of an eco-friendly method by Fourier-Transform Infrared (FT-IR) transmission spectroscopy for the determination of doxycycline in raw material. The raw material quality directly determines the quality of the drug. Through this analysis the method was completely validated according to the International Conference on Harmonization quidelines, showing accuracy, precision, selectivity, robustness and linearity. It was linear over the concentration range of $0.5-2.5 \mathrm{mg}$ with correlation coefficient 0.9991 and limits of detection and quantification of 0.125 and $0.378 \mathrm{mg}$, respectively. Fourier-Transform Infrared (FT-IR) transmission spectroscopy method is considered environmentally friendly because it uses only the potassium bromide as reagent, which is cheap and safe for the operator, does not expose the operator to toxic solvents or harmful reagents, and optimizes equipment for being a rapid analysis. The validated method is useful to the routine quality control of doxycycline.
\end{abstract}

Keywords: Antibiotic; Analytical method greener; Doxycycline; Environmentally friendly; Infrared spectroscopy; Method validation

\section{Introduction}

Doxycycline (DOX, Figure 1) is a broad spectrum antibiotic used in several countries. It has been used to treat infectious diseases and as an additive in animal nutrition to facilitate growth $[1,2]$

This drug is part of the list of medicines of the public health system in Brazil, and it is free delivery in the public with a medical prescription. Thus, it is extremely important quality control of this medicine to be able to ensure their effectiveness and safety [3].

Liquid chromatography method for the determination of DOX is the choice of some pharmacopoeias and methods described in the literature [2,4-12]. The official specification for the doxycycline hyclate present in dosage form is from $95.0 \%$ to $105.0 \%$ [6]. However, HPLC demands expensive equipment and columns, organic solvents in the preparation of solutions and/or mobile phases and the analysis time is longer than the carried out on Infrared spectroscopy or Ultraviolet spectrophotometric or Thin layer chromatography [13], which generates a greater time spent by analysts in performing the test and the lower logistics of equipment usage [1].

The use of organic solvents in drug analysis by laboratories and pharmaceutical industries is not a part of environmentally friendly techniques, since they generate toxic residues [14-16] which does not contribute to the future of the environment.

Infrared (IR) spectroscopy corresponds approximately to the part of the electromagnetic spectrum located between the visible and microwave regions. The peaks in the spectrum are excellent for the identification of the samples. The infrared spectroscopy is a method of identifying compounds which usually exhibits excellent features to be used on quality control of drugs and medicines [17]. Although the infrared spectroscopy is officially accepted to identification of several compounds, the literature shows few publications that employ this method for the quantitative analysis [18-20]. Moreover, it offers the possibility of obtaining spectra relatively quickly and contributes for the green chemistry $[18,21]$.

The green chemistry is defined as the creation, development and application of chemical products and processes to reduce or eliminate the use and generation of substances harmful to human health and the environment $[18,22]$.

IR method is considered environmentally friendly because it uses only the potassium bromide as reagent, which is cheap and safe for the operator, does not expose the operator to toxic solvents or harmful reagents, and optimizes equipment for being a rapid analysis.

A high quality pharmaceutical is only possible when it is made of a raw material of good quality and it is of extreme importance to have a method capable of monitoring its features. The objective of this research was to develop and validate an eco-friendly method by IR for the determination of DOX in raw material.

\section{Experimental}

\section{Equipments}

The equipments used were IRPrestige-21 ShimadzuTM, Fourier Transform Infrared Spectrophotometer detector and IRsolution software; an oven Nova ÉticaTM; and analytical balance model H51Mettler ToledoTM.

\section{Chemicals and Reagents}

The chemicals used were potassium bromide (analytical reagent, SynthTM), doxycycline hyclate 97\% (UniãoQuímicaTM Laboratory as reference chemical substance - RCS lot 0900002795) and the dosage form was doxycycline hyclate raw material also kindly donated by União QuímicaTM Laboratory lot 1300016656.

*Corresponding author: Ana Carolina Kogawa, Programa de Pós-graduação em Ciências Farmacêuticas, Faculdade de Ciências Farmacêuticas de Araraquara UNESP, Rodovia Araraquara-Jaú, km 1, CEP 14801-902, Araraquara, SP, Brazil, Tel: +55 163301 4681; Fax: +55 163301 6967; E-mail: ac_kogawa@yahoo.com.br

Received February 02, 2016; Accepted February 23, 2016; Published February 25, 2016

Citation: Kogawa AC, de Mello NP, Salgado HRN (2016) Quantification of Doxycycline in Raw Material by an Eco-Friendly Method of Infrared Spectroscopy. Pharm Anal Acta 7: 463. doi:10.4172/2153-2435.1000463

Copyright: () 2016 Kogawa AC, et al. This is an open-access article distributed under the terms of the Creative Commons Attribution License, which permits unrestricted use, distribution, and reproduction in any medium, provided the original author and source are credited. 
Citation: Kogawa AC, de Mello NP, Salgado HRN (2016) Quantification of Doxycycline in Raw Material by an Eco-Friendly Method of Infrared Spectroscopy. Pharm Anal Acta 7: 463. doi:10.4172/2153-2435.1000463

\section{Spectroscopy measurements}

It was performed a previous dilution of 1:10 with potassium bromide and doxycycline hyclate to facilitate the process of weighing and mitigate the possible errors.

The diluent was potassium bromide dried 24 hours before use.

The infrared spectra of reference and sample mixture pellets of $150 \mathrm{mg}$ weight were recorded with 40 scans at a resolution of 4.0. The absorbance values were obtained at $1714.72-1649.14 \mathrm{~cm}^{-1}$ range.

\section{Preparation of pellets}

A determined amount of powder (called diluted) was prepared by mixing doxycycline hyclate with dried potassium bromide powder at a concentration of $1: 10$. The diluted was placed in the oven at $105^{\circ} \mathrm{C}$ during 20 minutes. Then, appropriate dilutions were made with potassium bromide to obtain the working concentrations at $150 \mathrm{mg}$ tablets.

\section{Method validation}

Method validation was performed following International Conference on Harmonization (ICH) specifications [23] for linearity, selectivity, accuracy, precision, robustness, detection limit and quantification limit.

\section{Linearity}

Linearity was evaluated by regression analysis using five concentration points of doxycycline hyclate in triplicate ranging from 0.5 to $2.5 \mathrm{mg}$ prepared on three consecutive days. The values are reported as the mean of the calibration curves. The data were analyzed at 1714.717-1649.138 $\mathrm{cm}^{-1}$. Correlation coefficient and analysis of variance (ANOVA) were calculated and presented.

\section{Selectivity}

Selectivity was evaluated by comparing the spectra of the doxycycline hyclate RCS with that of the doxycycline hyclate sample exposed to light for 60 days. The spectra obtained were compared.

\section{Accuracy}

The accuracy was determined by measuring the doxycycline hyclate RCS at three levels from 80 to $120 \%$ of the method concentration (1.5 $\mathrm{mg}$ ), according to ICH recommendations [23]. Samples with 0.2, 0.5 and $0.8 \mathrm{mg}$ were added to $1.0 \mathrm{mg}$ of the standard sample and then made up to $150 \mathrm{mg}$ with potassium bromide. The final concentrations of $1.2,1.5$, and $1.8 \mathrm{mg}$, correspond to 80,100 , and $120 \%$ of the target concentration, respectively. The mean recoveries were determined.

\section{Precision}

Precision was evaluated with respect to both repeatability and intermediate precision. Repeatability (intra assay) was evaluated by analyzing all the diluted in the same day and identical working condition. Intermediate precision (inter assay) was studied by repetition of the assays on two different days by two analysts. Six replicates at a concentration of $1.5 \mathrm{mg}$ were prepared and assayed. The percentages of relative standard deviation (R.S.D.) of the analytical responses were analyzed.

\section{Robustness}

The robustness was evaluated by analyzing data after changing the time of compression, pressure, and the brand of potassium bromide.
Doxycycline hyclate diluted at concentration of $1.5 \mathrm{mg}$ was used in these experiments.

\section{Limits of detection and quantification}

The limit of detection (LOD) and the limit of quantification (LOQ) of the method were obtained from Equations (1) and (2):

$$
\begin{aligned}
& \mathrm{LOD}=3(\text { S.D. } / \alpha)(1) \\
& \mathrm{LOQ}=10(\text { S.D. } / \alpha)(2)
\end{aligned}
$$

where S.D. is intersection standard deviation and $\alpha$ is the average slope, obtained from calibration curves of the linearity study.

\section{Results and Discussion}

Previously described methods for the determination of doxycycline demand time and the use of toxic solvent. In this paper, IR spectroscopy was chosen in order to reduce the time, cost and environmental impact for the sample analysis.

All the data was obtained monitoring the carbonyl band between $1714.717-1649.138 \mathrm{~cm}^{-1}$. The values of these bands/peaks were provided in absorbance.

\section{Method development}

After identifying the carbonyl band, the analytical method was validated according to $\mathrm{ICH}$ recommendations [23].

\section{Method validation}

Linearity: The analytical curves generated on three consecutive days by plotting the mean absorbance values of spectra 1714.717-1649.138 $\mathrm{cm}^{-1}$ against concentration yielded correlation coefficients greater than 0.9991. Additionally, the data were validated by means of analysis of variance (Table 1$)$, which showed significant linear regression $\left(\mathrm{F}_{\text {calculated }}\right.$ $\left.>\mathrm{F}_{\text {critical }}, \mathrm{P}=5 \%\right)$ and no significant lack of fit $\left(\mathrm{F}_{\text {calculated }}<\mathrm{F}_{\text {critical }}, \mathrm{P}=5 \%\right)$.

Selectivity: The spectra analysis did not show variations in the spectrum even after a long period to light exposition (Figure 2). The carbonyl bands of standard and sample overlap perfectly and they can be considered equivalent. The carbonyl band, as shown in linearity parameter proved by ANOVA, exhibits absorbance values increasing with the increase of drug and vice versa. Thus, if the bands overlap it can be concluded that the sample was not degraded in this period of exposure to light.

Accuracy: The accuracy of the method was confirmed by determining the average recoveries from the samples by applying the standard addition method. As shown in Table 2, the mean percentage recoveries of doxycycline hyclate was in accordance with fixed limits from 98.0 to $102.0 \%$ [24,25], indicating the suitability of the developed method in quantifying the concentration of doxycycline in pharmaceutical raw material.

Precision: Repeatability of the analytical method was found to be reliable based on \% R.S.D. ( $<5 \%)$. Two analysts demonstrated intermediate precision on different days. The \% R.S.D. values were less than $5 \%$, confirming that the method is sufficiently precise (Table 3 ).

The accuracy values are always associated with precision values. The higher the concentration of analyte in the sample, the lower is the deviation permitted in the results of its analysis. For pharmaceuticals, the range accepted for the accuracy parameter is $98-102 \%[24,25]$.

Robustness: The results obtained in robustness test are shown in 
Citation: Kogawa AC, de Mello NP, Salgado HRN (2016) Quantification of Doxycycline in Raw Material by an Eco-Friendly Method of Infrared Spectroscopy. Pharm Anal Acta 7: 463. doi:10.4172/2153-2435.1000463

Page 3 of 4

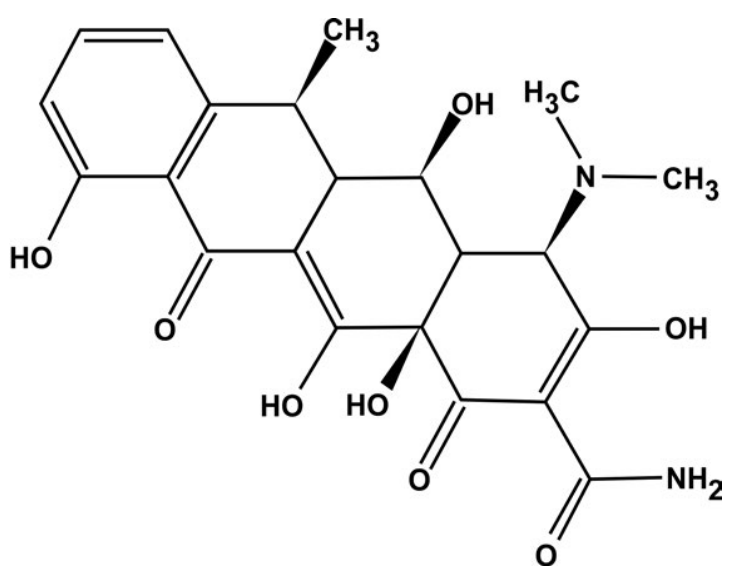

Figure 1: Comparison between thermogravimetry-derivative (a) and differential thermal analysis-derivative (b) curves of smectite MX-80 up to $1000^{\circ} \mathrm{C}$.

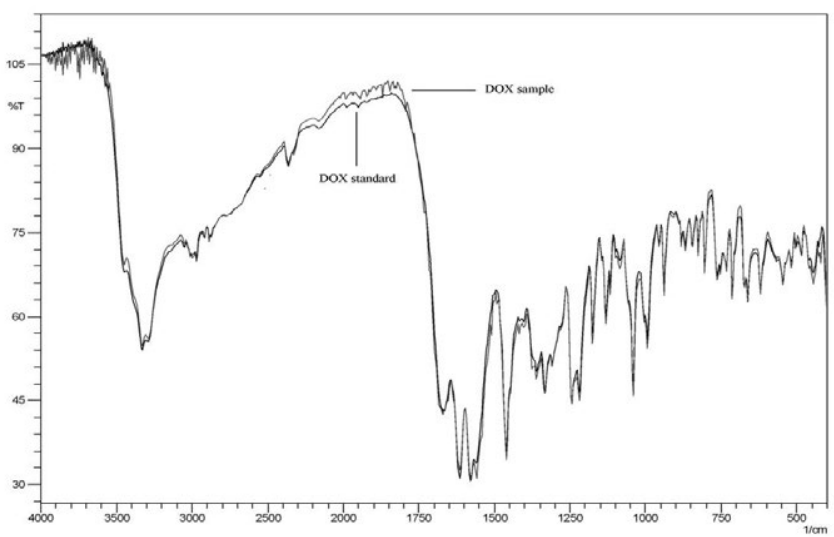

Figure 2: Overlapping FT-IR spectrum doxycycline standard and sample.

Table 4. Statistical analysis was performed to evaluate the influence of variation of the $\mathrm{KBr}$ brand, time of compression and pressure. The robustness was confirmed by $\mathrm{F}$ test (Snedecor) homogeneity of variance and $\mathrm{t}$ (Student) to compare the mean, which showed $\mathrm{F}_{\text {calculated }}<$ $\mathrm{F}_{\text {critical }}, \mathrm{P}=5 \%$ and $\mathrm{t}_{\text {calculated }}<\mathrm{t}_{\text {critical }}, \mathrm{P}=5 \%$. Thus, the mean is equivalent.

Limits of detection and quantification: LOD and LOQ values were found to be respectively 0.125 and 0.378 for doxycycline hyclate in raw material $\left(1714.717-1649.138 \mathrm{~cm}^{-1}\right)$. The values are close to zero, which indicate the sensitivity of the method.

\section{Conclusion}

The IR spectroscopy method was successful developed and validated for quantitative determination of doxycycline in raw material. The method presented linearity, selectivity, accuracy, precision, robustness and adequate detection and quantification limits.

This method has some important advantages over other methods described in the literature, such as its simplicity, low cost and does not demand the use of any toxic chemicals that are harmful to the environment. It can be considered a sustainable analytical method with no side effects.

To conclude, it was developed an environmentally friendly method

\begin{tabular}{|c|c|}
\hline Parameter & $1714.717-1649.138 \mathrm{~cm}^{-1}$ \\
\hline Linearity range (mg) & $0.5-2.5$ \\
\hline Slope & 0.1869 \\
\hline Intercept & 0.0150 \\
\hline Correlation coefficient $(r)$ & 0.9991 \\
\hline Regression & $2502.67(4.96)$ \\
\hline Lack of fit & $2.48(3.71)$ \\
\hline
\end{tabular}

*Values are reported as mean of three calibration curves generated on three consecutive days

Table 1: Linearity parameters for the determination of doxycycline* and summary of ANOVA.

\begin{tabular}{|c|c|c|c|c|}
\hline Samples at 1.0 mg & $\begin{array}{c}\text { References standard } \\
\text { concentration } \mathbf{( m g )} \\
\text { Added Found }\end{array}$ & $\begin{array}{c}\text { R.S.D } \\
\mathbf{( \% )} \\
\mathbf{n = 3}\end{array}$ & $\begin{array}{c}\text { Recovery } \\
\text { (\%) }\end{array}$ & $\begin{array}{c}\text { Mean } \\
\text { recovery } \\
\text { (\%) }\end{array}$ \\
\hline $\begin{array}{c}\text { Doxycycline } \\
(1714.717-1649.138 \\
\left.\text { cm }^{-1}\right)\end{array}$ & 0.200 .20 & 2.05 & 99.01 & \\
\hline & 0.500 .49 & 2.58 & 99.19 & 99.63 \\
\hline
\end{tabular}

Table 2: Method accuracy results for doxycycline in raw material.

\begin{tabular}{|c|c|c|c|c|c|c|c|c|}
\hline Band & Level & \multicolumn{5}{|c|}{ Absorbance } & $\begin{array}{c}\text { R.S.D } \\
\text { (\%) }\end{array}$ \\
\hline & & 1 & 2 & 3 & 4 & 5 & 6 & \\
\hline \multirow{2}{1714.717-}{} & Repeatability & 0.547 & 0.548 & 0.535 & 0.525 & 0.556 & 0.568 & 2.23 \\
$\begin{array}{c}1649.138 \\
\mathrm{~cm}^{-1}\end{array}$ & $\begin{array}{c}\text { Intermediated } \\
\text { precision }\end{array}$ & 0.529 & 0.530 & 0.544 & 0.535 & 0.555 & 0.546 & 3.96 \\
\cline { 2 - 9 } & & 0.505 & 0.573 & 0.525 & 0.536 & 0.543 & 0.493 & \\
\hline
\end{tabular}

Table 3: Method precision results for doxycycline hyclate.

\begin{tabular}{|c|c|c|c|c|c|c|}
\hline \multirow[t]{2}{*}{ Test } & \multicolumn{2}{|c|}{$\mathrm{KBr}$ brand } & \multicolumn{2}{|c|}{$\begin{array}{l}\text { Time compression } \\
(\text { min) }\end{array}$} & \multicolumn{2}{|c|}{ Pressure $(\mathrm{KN})$} \\
\hline & Synth & Shimadzu & 15 & 10 & 100 & 95 \\
\hline Fcal & \multirow{5}{*}{\multicolumn{2}{|c|}{$\begin{array}{c}12.09 \\
19.00 \\
0.83 \\
2.78\end{array}$}} & \multirow{5}{*}{\multicolumn{2}{|c|}{$\begin{array}{c}5.42 \\
19.00 \\
0.75 \\
2.78\end{array}$}} & \multirow{5}{*}{\multicolumn{2}{|c|}{$\begin{array}{c}6.98 \\
19.00 \\
0.18 \\
2.78\end{array}$}} \\
\hline Ftab & & & & & & \\
\hline tcal & & & & & & \\
\hline & & & & & & \\
\hline ttab & & & & & & \\
\hline
\end{tabular}

Table 4: Robustness results.

for routine analysis of quality control of doxycycline in pharmaceutical industries and laboratories.

\section{Acknowledgement}

The authorsacknowledge CNPq (Brasilia, Brazil), FAPESP (São Paulo, Brasil), CAPES (São Paulo, Brasil) and PADC/FCF/UNESP (Araraquara, Brazil).

\section{Conflict of Interest}

The authors report no conflict of interest.

\section{References}

1. Kogawa AC, Salgado HR (2013) Quantification of doxycycline hyclate in tablets by HPLC-UV method. J Chromatogr Sci 51: 919-925.

2. Fiori J, Grassigli G, Filippi P, Gotti R, Cavrini V (2005) HPLC-DAD and LC-ESIMS analysis of doxycycline and related impurities in doxipan mix, a medicated premix for incorporation in medicated feedstuff. J Pharm Biomed Anal 37: 979985

3. Kogawa AC, Salgado HRN (2012) Doxycycline hyclate: a review of properties applications and analytical methods. Int J Life Sci Pharma Res 2:11-25.

4. Ramesh PJ, Basavaiah K, Tharpa K, Vinay KB, Revanasiddappa HD (2010) Development and validation of RP-HPLC method for the determination of doxycycline hyclate in spiked human urine and pharmaceuticals. JPCCR 4:101-107.

5. Portuguese Pharmacopoeia (2005) Infarmed: Lisboa.

6. British Pharmacopoeia (2010) Her Majesty's Stationary Office: London. 
Citation: Kogawa AC, de Mello NP, Salgado HRN (2016) Quantification of Doxycycline in Raw Material by an Eco-Friendly Method of Infrared Spectroscopy. Pharm Anal Acta 7: 463. doi:10.4172/2153-2435.1000463

Page 4 of 4

7. The United States Pharmacopeia (2010) United States Convention Inc:Rockville MD.

8. Croubels S, Vermeersch H, De Backer P, Santos MD, Remon JP, et al. (1998) Liquid chromatographic separation of doxycycline and 4-epidoxycycline in a tissue depletion study of doxycycline in turkeys. J Chromatogr B Biomed Sci Appl 708: 145-152.

9. Santos MD, Vermeersch H, Remon JP, Schelkens M, De Backer P, et al. (1996) Validation of a high-performance liquid chromatographic method for the determination of doxycycline in turkey plasma. J Chromatogr B Biomed Appl 682: 301-308.

10. Denobile M, Nascimento ES (2004) Method validation for the determination of residues of antibiotics oxytetracycline, tetracycline, chlortetracycline and doxycycline in milk by high-performance liquid chromatography. Braz J Pharm Sci 40:209-218.

11. Monser L, Darghouth F (2000) Rapid liquid chromatographic method for simultaneous determination of tetracyclines antibiotics and 6-epi-doxycycline in pharmaceutical products using porous graphitic carbon column. J Pharm Biomed Anal 23:353-362.

12. Kogawa AC, Salgado HR (2013) Quantification of doxycycline hyclate in tablets by HPLC-UV method. J Chromatogr Sci 51: 919-925.

13. Kogawa AC, Mendonça JN, Lopes NP, Salgado HRN (2014) Stability-indicating thin-layer chromatographic method for determination of darunavir in complex darunavir-b-cyclodextrin in the presence of its degradation products. Anal Methods 6: 3689-3693.

14. Tótoli EG, Salgado HRN (2013) Development and validation of a rapid turbidimetric assay to determine the potency of ampicillin sodium in powder for injectable solution. Anal Methods 5: 5923-5928.

15. Sversut RA, Amaral MS, Baroni ACM, Rodrigues PO, Rosa AM, et al. (2014) Stability-indicating HPLC-DAD method for the simultaneous determination of fluoroquinolones and corticosteroids in ophthalmic formulations. Anal Methods 6: 2125-2133.

16. Dichiarante V, Ravelli D, Albini A (2010) Green chemistry: state of the art through an analysis of the literature. Green Chem Lett Rev 3: 105-113.

17. Igne B, Talwar S, Feng H, Drennen JK, et al. (2015) Near-Infrared Spatially Resolved Spectroscopy for Tablet Quality Determination. J Pharm Sci 104: 4074-4081.

18. Kogawa AC, Salgado HRN (2014) Comparative study over methods developed for quantification of darunavir in tablets by environmental friendly infrared and capillary electrophoretic techniques. JIRMEPS 2: 99-105.

19. Tótoli EG, Salgado HRN (2012) Development and validation of the quantitative analysis of ampicillin sodium in powder for injection by Fourier-transform infrared spectroscopy (FT-IR). Physical Chemistry 2: 103-108.

20. Moreno AH, Salgado HRN (2012) Development and validation of the quantitative analysis of ceftazidime in powder for injection by infrared spectroscopy. Physical Chemistry 2: 6-11.

21. Kogawa AC, Salgado HRN (2013) Development and validation of infrared spectroscopy method for the determination of darunavir in tablets. Physical Chemsitry 3: 1-6.

22. Gałuszka A, Migaszewski Z, Namies'nik J (2013) The 12 principles of green analytical chemistry and the significance mnemonic of green analytical practices. Trend Anal Chem 50: 78-84.

23. ICH Guidelines (2005) International Conference on Harmonization. Validation of Analytical Procedures, Text and Methodology Q2 (R1), Geneva Switzerland.

24. Horwitz W, Kamps LR, Boyer KW (1980) Quality assurance in the analysis of foods and trace constituents. J Assoc Off Anal Chem 63: 1344-1354.

25. AOAC (2002) Association of official analytical chemists, Official Methods of Analysis Gaithersburg: AOAC. 